\title{
Improved GA based power and cost management system in a grid-associated PV-wind system
}

\author{
Kothai Andal C, Jayapal R \\ Department of Electrical and Electronics Engineering, RV College of Engineering, Bengaluru, VTU, Belagavi, \\ Karnataka, India
}

\section{Article Info \\ Article history: \\ Received May 4, 2021 \\ Revised Aug 28, 2021 \\ Accepted Sep 5, 2021}

\section{Keywords:}

Economic benefits Improved genetic algorithm Hybrid power system Intelligent power and cost management

Time-of-use tariff

\begin{abstract}
Renewable hybrids play an essential part in assisting India with quickening the decarbonization of power production and lowering power production expense in the medium term. PV and wind energy are complementary to each other, making the system to generate electricity almost throughout the year. In this paper, a grid-associated PV-wind energy system tied with a battery is analyzed. $\mathrm{PV}$, wind, grid and battery are the sources to be effectively scheduled for uninterrupted power and cost minimization. Energy management controllers use optimization strategies for effective utilization of sources and cost minimization. The methodologies are detailed as optimization problems. Limiting the household energy cost is considered as objective, and the delivery ratio of power offered to the grid and utilized locally is treated as the optimization variable. In this paper, an improved genetic algorithm is proposed to solve the formulated nonlinear optimization problems. The time-of-use tariff is becoming popular in India; therefore, this article analyses the improved genetic algorithm based intelligent power and cost management system under time-of-use tariff. Using MATLAB, the proposed approach's performance is presented with the comparative analysis of conventional self-made for selfconsumed and rest for sale mode and genetic algorithm-based energy management controller.
\end{abstract}

This is an open access article under the CC BY-SA license.

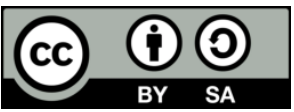

Corresponding Author:

Kothai Andal C

Department of Electrical and Electronics Engineering

RV College of Engineering, Bengaluru

VTU, Belagavi, Karnataka, India

Email: kothaiandal@gmail.com

\section{INTRODUCTION}

Integration of various sustainable power sources to satisfy customers' energy requirements in remote places is becoming increasingly common these days [1]. Because wind and sun energy is opposed, the organization can generate electricity almost all year. Due to the discontinuous nature of both solar and wind energy sources, the use of an energy storage structure (ESS) is common in standalone applications [2]-[5]. In the meanwhile, owing to the inherent characteristics of available renewable sources, such as eccentricity and fluctuation, running hybrid renewable energy systems with greater reliability is a big issue. As a consequence, there are several control mechanisms available to ensure a smooth power transfer. The wind energy conversion system (WECS) requires a regulator capable of ensuring its activity mode around the optimal operating point in order to maximize the amount of energy delivered from a wind turbine as indicated by wind speed vacillations. Three forms of maximum power point tracking (MPPT) have been extensively studied in the literature: tip speed ratio, power signal feedback control, and hill-climbing search [6]-[8]. However, it necessitates wind speed, which increases the expense and complexity of implementation. 
A fast and effective fuzzy-based MPPT technique is devised to overcome the previously described concerns [9].

Several researchers suggested soft computing-based MPPT algorithms to extract a large quantity of solar energy [10]-[14]. Mirjalili and Lewis [15], created the whale optimization algorithm (WOA) in 2016. WOA is driven by the remarkable hunting behavior of humpback whales, and it is commonly used to solve nonlinear optimization problems. WOA is proposed in this article to extract maximum power from a PV array. Many studies explored how to reduce the use of fuel and so reduce $\mathrm{CO}_{2}$ emissions while maintaining a high degree of reliability and power eminence for microgrids. This is achieved by increasing the use of renewable resources, dispatching and scheduling petroleum product generators at their optimal productivity working points, and storing excess energy in a storage system while reducing dependency on the utility network. Several researchers used a genetic algorithm to optimize the multi-source system's cost and sizing [16].

At the time of installation, cost minimization is planned through appropriate size and position. After installation, an energy management plan for a hybrid system [17]-[19] is utilized to decrease costs and meet demand. In investigated an energy management system for a microgrid with PV and battery storage based on model predictive control (MPC). The objective of EMS in the microgrid is to provide reliable and optimum generation from different sources [20]. In a grid-associated private PV-wind power structure, optimization plays a vital role in energy storage, delivery schedule, load management, charging of the battery and optimizing the percentage of the purchasing power from the utility grid. In reality, energy prices have a huge impact on the financial success of PV-wind power networks [21].

When used properly, energy tariffs for a network-connected private PV-wind power system can provide significant financial benefits to energy consumers. Feed-in tariff schemes, which were first implemented in Germany in 1990, require electric utilities to acquire all renewable-generated power at a fixed price per $\mathrm{kWh}$. However, one common criticism of the feed-in tariff is that it does not produce enough competition [22]. In a grid-associated sustainable power network, the percentage of buy to sell expenses and the building electrical load profile are important boundaries. When the price for acquiring power is more significant than for selling, where the tariff is time dependent, the cost-effectiveness of a grid-connected PV array is improved by restricting surplus PV power taken care of to the network dominantly [23]. The time-ofuse (TOU) tariff is becoming a popular way to buy electricity all over the world. They can improve the energy efficiency of power networks from a strategic standpoint, resulting in emission reductions [24].

Self-made for self-consumed and rest for sale (SFC\&RFS) is an existing system in India, where the excess energy is stored in a battery; after reaching battery maximum capacity, rest power is given to the grid. In the case of power demand, energy stored in a battery is utilized till minimum battery power, then purchased from the grid. In [25] analyzed the energy management of a grid-connected PV system with a battery, employing an approach similar to the SFC\&RFS method, to reduce a household's operational energy losses. In both cases, excess power and demand in the power system work irrespective of tariff. When the battery is fully charged, it may be necessary to purchase electricity from the grid at a high tariff, reducing the cost advantage to the consumer. To increase the cost benefit of the consumer. Analyzed optimal energy management controller grid- associated private PV system with energy storage [26].

Zhang and Tang [26] employed a genetic algorithm (GA) for energy management control, and the results were compared to the conventional SFC\&RFS mode. GA is widely used to address a variety of optimization issues due to its user-friendliness and positive outcomes. For GAs, premature convergence is wellknown [27], which is where the issue of hanging about the local optimum rather than the global optimal comes from. Hanging around the local optimum in a cost optimization issue decreases the consumer's daily cost benefit in this application. This research proposes a multiparent crossover approach-based GA, entitled Improved GA, to address this issue and enhance the cost benefit. The energy management techniques and economic benefits of a grid-connected private PV-wind power structure with battery storage utilizing improved GA are discussed in this paper. The daily cost benefit of the customer is discussed here with the improved GA based energy management system in comparison to the conventional SFC\&RFS mode and GA.

\section{RENEWABLE HYBRID POWER SYSTEM}

In this analysis, direct current (DC) integration is chosen for variable speed drive wind turbines that include a converter-inverter. Improved equipment, lower costs, and increased energy production are all advantages of the DC-coupling system. A typical DC connection is used to coordinate the DC yield of the wind, solar PV plant, and batteries in this design. To convert this DC power into alternating current (AC) power, a typical inverter with joined yield AC capacity is used. The Block diagram of the proposed system is shown in Figure 1.

Wind, solar PV plant and batteries are connected with DC bus through DC-DC converter for voltage matching. Battery charging from the DC bus alone employs a DC-DC buck converter. Inverter after DC bus 
uses LCL filter for sine wave shaping and harmonic reduction. From Figure 1, it is observed that each power system, battery charging and discharging, grid connection and load are controlled using intelligent power and cost management system.

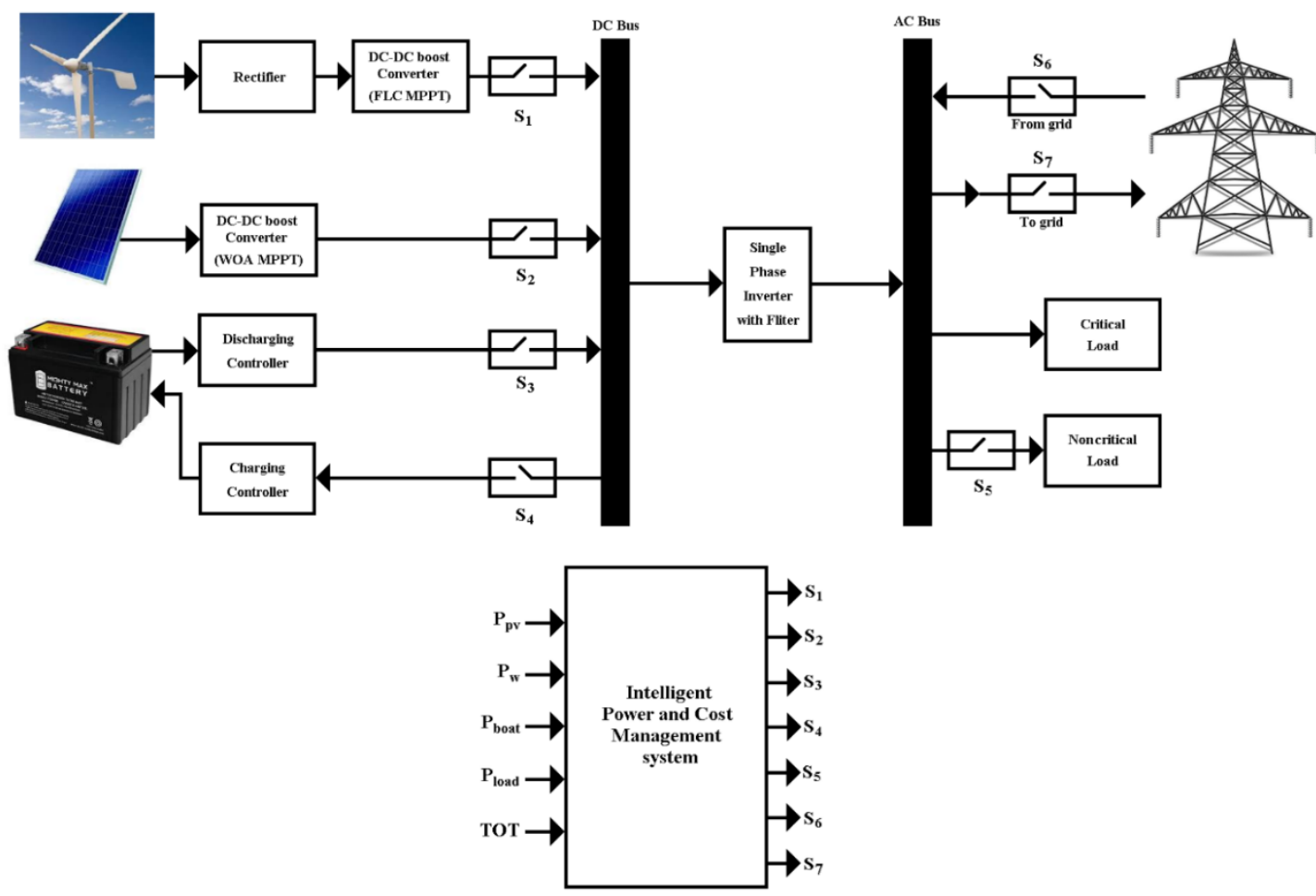

Figure 1. Block diagram of grid associated PV and wind power system coupled with battery

\subsection{Wind energy system}

The WECS comprises a variable speed wind turbine, a permanent magnet synchronous generator (PMSG), a DC-DC boost converter and a controller. The power extracted from the wind is [28]

$$
P_{W}=\frac{1}{2} \rho A v^{3} C_{p}(\lambda, \theta)
$$

where $\rho$ is the air density in $\mathrm{kg} / \mathrm{m} 3, \mathrm{~A}$ is the area swept by the rotor blades in $\mathrm{m} 2$, and $\mathrm{v}$ is the wind velocity in $\mathrm{m} / \mathrm{s}$. $\mathrm{Cp}$ is the power coefficient and is a function of tip speed ratio (TSR, $\lambda$ ) and pitch angle $(\theta)$. The schematic of the wind energy system is shown in Figure 2 (a). A PMSG is chosen because of its minimal operational and support costs [29]. The generator yield is reliant on the breeze speed. The three-stage yield of the generator is rectified utilizing a diode rectifier, and the voltage level is then enhanced with the help of a DC-DC support converter, as seen in Figure 2 (a).

To extract maximum power from wind energy produced, an MPPT method is applied. Once the wind speed is lesser than the rated value, it is important for the wind turbine to quickly follow the wind speed change to provide maximum power to load or grid. In this analysis, the fuzzy logic controller is employed as MPPT Mamdani method of fuzzy is selected for MPPT, whose output is defined by linguistic variable to offer fine-tuned output, while conventional methods produce predefined step change. The optimum duty ratio is produced by 49 tuned fuzzy rules.

\subsection{PV Power system}

PV power structure consists of PV array, DC-DC boost converter with MPPT control, as shown in Figure 2 (b), which is connected with the DC bus. MPPT method tracks maximum power and offers voltage regulation through the boost converter, making the PV system suitable for grid/load connection. A PV module comprises several PV cells associated in series and parallel to get the necessary voltage and current. Every PV cell is fundamentally a p-n diode. Single-diode mathematical model is material to mimic silicon PV cells, which comprises a photocurrent source $I_{\text {ph }}$, a nonlinear diode, and internal resistances $R s$ and $R_{\text {sh. }}$ The PV module's current $I$ under discretionary working conditions can be portrayed as [31]. 


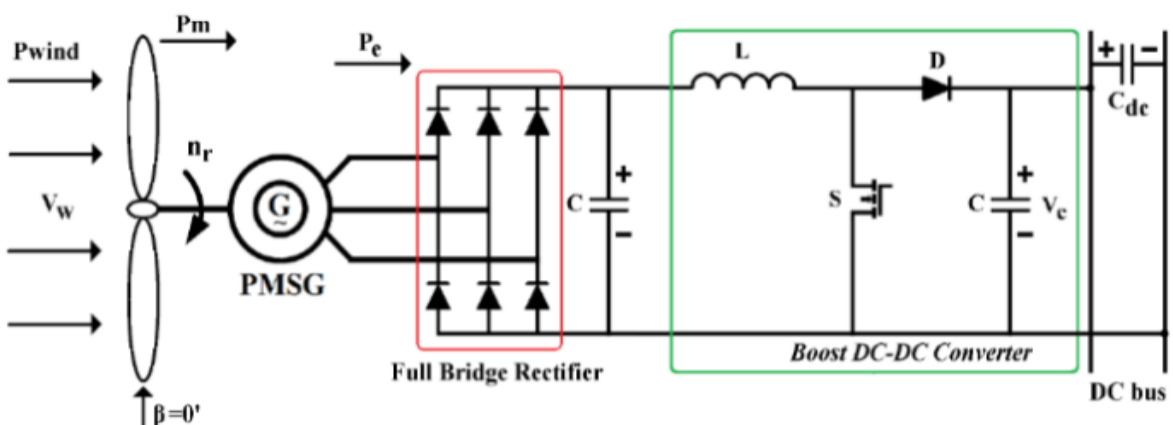

(a)

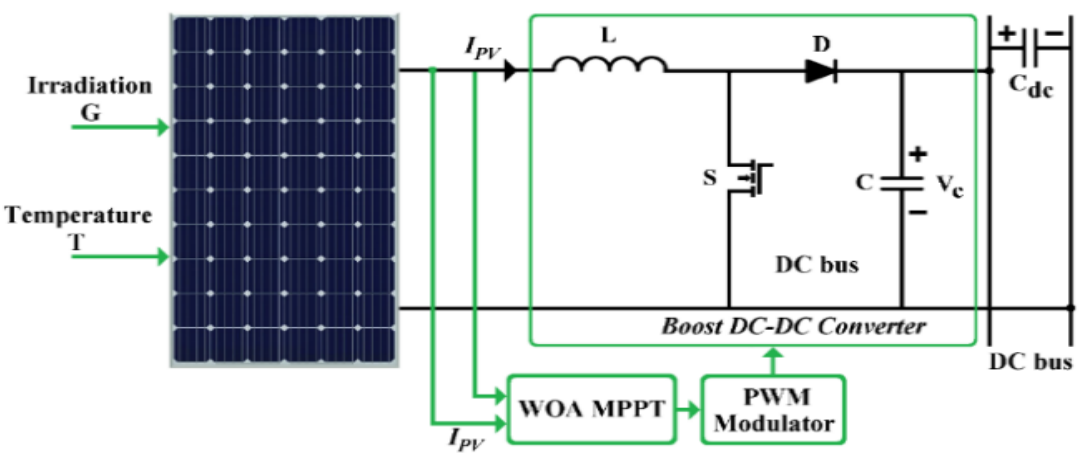

(b)

Figure 2. Renewable energy system; (a) wind energy system [30], (b) PV power system

$$
I=I_{p h}-I_{o}\left(e^{\frac{q\left(V+I R_{S}\right)}{k T}}-1\right)-\frac{V+I R_{S}}{R_{S h}}
$$

As shown in (2) $I_{o}$ is diode saturation current, $\mathrm{Q}$ is the charge of electron $=1.6 \times 10^{19}$ (Coulomb), $\mathrm{K}$ is Boltzmann constant $(\mathrm{J} / \mathrm{K})$ and $\mathrm{V}$ is cell output voltage $(\mathrm{V})$. In this paper, 12 panels are connected in a seriesparallel configuration. Each panel is a rated power of $340 \mathrm{~W}$ and a maximum voltage (Vmp) of $38.2 \mathrm{~V}$. The WOA is offered as an MPPT approach in the PV power structure in this study. WOA is inspired by humpback whales' bubble-net hunting technique [15]. The regulator detects the relative voltage and currents for each population of whales, i.e., duty ratios, and estimates yield power. WOA is used as an instantaneous control MPPT technique in this study, i.e., duty cycle control using a population of whales as duty ratios to reduce consistent state oscillations. Direct control MPPT reduces power loss and hence increases the system's productivity.

\subsection{Battery energy storage system (BESS)}

The battery stores an overabundance of energy and supplies the load when the produced energy isn't sufficient for the load. Intelligent power and cost management systems keep power within a defined window, avoiding over-discharge or overcharge control. When the power required by the load is less than the electricity generated by the PV cluster and wind generator, the battery is charged through the DC bus. This procedure is repeated until the battery reaches PBAT-MAX; once the battery reaches its maximum power, it is disconnected from the bus to avoid overcharging, and excess power from sources is delivered to the grid. Batteries have connected again when battery power decreases below $\mathrm{P}_{\text {BAT-MAX. The battery gets charging }}$ when the power needed by the load is more noteworthy than the power produced by the PV cluster and wind generator. To secure the battery against over-discharging, the battery is separated when its power falls underneath $\mathrm{P}_{\mathrm{BAT}-\mathrm{MIN}}$. At this condition, the load is supplied from renewable energy sources and the grid. The inverter-converts generated energy from DC to AC for an AC load [32].

\section{INTELLIGENT POWER AND COST MANAGEMENT SYSTEM UNDER TOU TARIFF}

The PV power system, wind energy system, and battery energy storage system mentioned above are all connected by a DC bus. Each is individually controlled through intelligent power and cost management system under the TOU tariff. When renewable energy is overabundance than the load demand, the excess 
energy is stored in the batteries or vended to the grid. The amount of energy charging the battery or vended to the grid is decided by the delivery ratio (b), which is considered as an optimization variable. When the renewable energy is lesser than the load demand, battery or grid supplies the rest of the energy to load which is decided by intelligent power and cost management system based on a tariff. In this section cost benefit for the owner of a renewable energy system is discussed with the help of a cost and energy management system.

Power generated from renewable energy sources $\left(P_{\text {ren }}\right)$, load power $\left(P_{L}\right)$, power purchased from the grid $\left(P_{G}\right)$, power vended to grid $\left(P_{\text {sell }}\right)$ and power stored in the battery $\left(P_{B A T}\right)$ are the major power parameters that decide the performance of the grid. Power purchased from the grid $\left(\mathrm{P}_{\mathrm{G}}\right)$ and power sold to the grid $\left(\mathrm{P}_{\text {sell }}\right)$ are the two prime factors that directly affect the overall grid cost. The cost benefit is controlled indirectly by battery charging and discharging power.

- Mode 1: Consider over the period $\left[t_{0}, t f\right]$, whereby the renewable output exceeds the load demand then power sold to grid is

$$
P_{\text {sell }, t}=\left(P_{\text {ren,t }}-P_{L, t}\right) \cdot \mathrm{b}_{t}
$$

where $b_{t}$ is the delivery ratio. It is the optimization variable of the power and cost management optimization problem and is limited by

$$
0 \leq \mathrm{b}_{t} \leq 1
$$

Then, the remaining part of power, $\left(P_{\text {ren,t }}-P_{L, t}\right)$, is further delivered through $\mathrm{b}_{t}$ to battery as

$$
-P_{B A T, t}=\left(P_{r e n, t}-P_{L, t}\right) \cdot\left(1-b_{t}\right)
$$

where $-P_{B A T, t}$ is the charging power of the battery storage. Selling cost of energy at the instant $\mathrm{t}$ is

$$
F_{\text {sell }, t}=P_{\text {sell,t }} \cdot F_{0}
$$

where $F_{\text {sell,t }}$ is the electricity sale cost and $F_{0}$ is the selling price of $\mathrm{PV}$ and wind power.

- Mode 2: When the renewable output is less than the load demand, i.e., $\left(P_{\text {ren,t }}-P_{L, t}<0\right)$, the battery storage is changed to discharging state. To fulfill the load requirement, extra electricity will most likely be purchased from the grid. Purchasing electricity from the grid at the instant $t$ is

$$
P_{G, t}=P_{L, t}-P_{\text {ren }, t}-P_{B A T, t}
$$

profound drain or excessive charging reduces the battery's operating life and incurs additional maintenance costs. As a result, it is a good idea to set the battery power status limitations as shown in (8).

$$
P_{B A T M I N} \leq P_{B A T, t} \leq P_{B A T M A X},
$$

where $P_{B A T, t}$ is the battery power at $t . P_{B A T M I N}, P_{B A T M A X}$ form a boundary for $P_{B A T, t}$. The buying price of energy from the grid at the instant $\mathrm{t}, F_{b u y, t}$ is influenced by the electricity tariff. It is attained by

$$
F_{\text {buy }, t}=P_{G, t} \cdot F_{\text {price }, t}
$$

$F_{\text {price, } t}$ is the electricity tariff at $t$. In this analysis, $F_{\text {price }, t}$ follows a TOU tariff rule.

\subsection{Cost benefit as objective function}

The total cost benefit of a grid-associated hybrid private power system during the period [t0, $\mathrm{tf}]$ is stated as shown in (10).

$$
F_{\text {total-TOU }}=\int_{t=t_{0}}^{t_{f}}\left(F_{\text {sell, } t}-F_{\text {buy }, t}\right) \cdot d t
$$

The total cost, $F_{\text {total }}$, is considered as the objective function of the power and cost management optimization function. Maximising $F_{\text {total }}$ accomplishes the optimal profit of the entire small scale power 
system. Consolidating the objective function (10) and constraints, the energy management optimization problem under TOU tariff is produced as shown in (11).

$$
\begin{gathered}
\max F_{\text {total-Tou }}\left(\mathrm{b}_{t}\right)=\int_{t=t_{0}}^{t_{f}}\left(F_{\text {sell }, t}-F_{\text {buy }, t}\right) \cdot d t, \\
\text { s.t. } \\
P_{G, t}+P_{\text {ren }, t}+P_{B A T, t}-P_{S E L L, t}-P_{L, t}=0, \\
\left(P_{\text {ren }, t}-P_{L, t}\right) \cdot\left(1-\mathrm{b}_{t}\right)+P_{B A T, t}=0, \\
\left(P_{\text {ren }, t}-P_{L, t}\right) \cdot\left(\mathrm{b}_{t}\right)-P_{S E L L, t}=0, \\
0 \leq \mathrm{b}_{t} \leq 1 \\
P_{B A T M I N} \leq P_{B A T, t} \leq P_{B A T M A X},
\end{gathered}
$$

The power and cost management optimization (11) are constrained nonlinear optimization problems. It is first digitised and then dealt with using mathematical computations in the following. In the energy management problem, the delivery ratio (b) is the optimization variable; the renewable power forecast and institutional load forecast are the inputs.

\subsection{Improved GA in power and cost management system}

The proposed improved GA based optimization algorithm is delineated in Figure 3; it makes out of the accompanying primary steps:

- Step 1: Initialisation

In this stage, the population is initialized, which comprises a set of chromosomes. It signifies an order for a problem to be solved. Apart from that, the parameters of GAs are also initialized for future application.

- Step 2: Fitness evaluation and selection operator

Following the determination of the energy source status, chromosome fitness is determined. At that point, the selection operator selects better chromosomes to be endured. The binary tournament operator [33] is active, which chooses the better chromosomes with higher objective values in this maximization problem.

- Step 3: Crossover operator

In this stage the two-point crossover operator toward mate two chromosomes which are self-assertively assigned. There is a crossover rate $(\mathrm{Pc})$ that resolves whether the crossover operator implements the mating of two chromosomes.

- Step 4: Mutation operator

A chromosome is planned to mutated when it is smaller than the mutation rate (Pm). Here, a well-known swap mutation operator is used. The approach entails creating arbitrary chromosomal cut-points and then swapping the genes that are suited to the dual cut-points.

- Step 5: Multi-parents crossover operator

A multiparent crossover operator is proposed to generate descendants from several parents. In this stage, the created descendants are deposited in an exterior store and utilized in the substitution state. The magnitude of the outside store is the same as the dimension of population. At that point, entire chromosomes are checked pair-astutely predictable with their succession results. At the point when an unnecessary solution is found throughout the pair-wise correlation, a chromosome is sequentially drawn from the outside store which has not been used and afterward supplanted in the overlapping arrangement.

With the help of the above steps improved GA finds out optimum $b$ for maximum cost, to offer enriched daily benefit. 


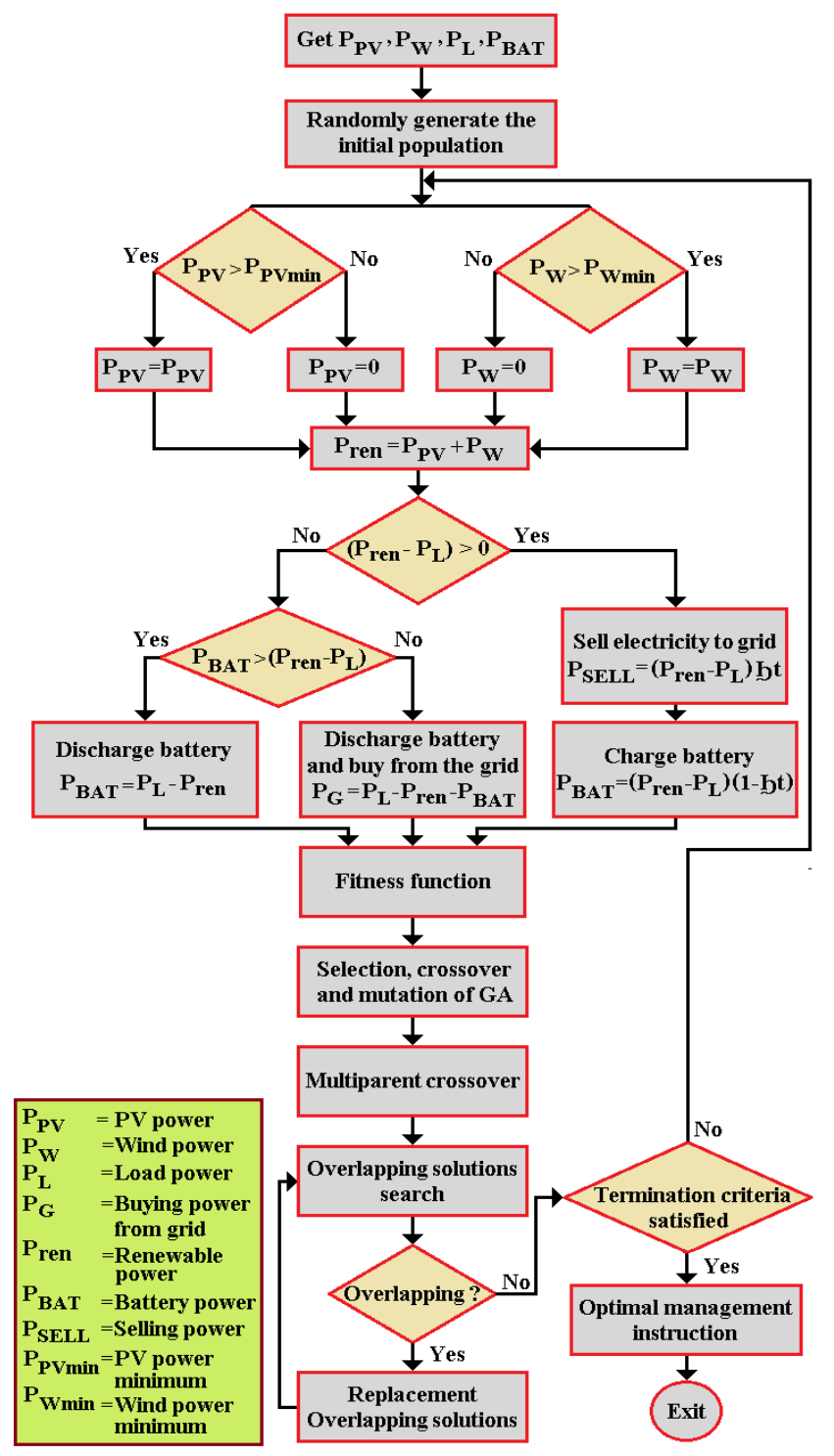

Figure 3. Flowchart of improved GA based optimization algorithm

\section{SIMULATION RESULTS AND ANALYSIS}

PV-wind grid-associated system tied with battery model is developed using MATLAB/Simulink. Specification of the hybrid power system is shown in Table 1.

Table 1. Specification of the hybrid power system

\begin{tabular}{lll}
\hline \multicolumn{1}{c}{ System } & \multicolumn{2}{c}{ Specification } \\
\hline PV & $4 \mathrm{~kW}$ & \\
Wind & $5 \mathrm{Hp}$ & Wind \\
Boost converter & $\mathrm{PV}$ & $110 \mathrm{uH}$ \\
Inductor & $100 \mathrm{uH}$ & $1000 \mathrm{uF}$ \\
Capacitor & $1000 \mathrm{uF}$ & $20 \mathrm{KHz}$ \\
Switching Frequency & $20 \mathrm{KHz}$ & \\
Battery & $2 \mathrm{kw}$ & \\
DC Bus & $330 \mathrm{~V} \mathrm{DC}$. & \\
Inverter & $1 \phi \quad$ Inverter, $50 \mathrm{~Hz}$, \\
& $230 \mathrm{~V}$ & \\
\hline
\end{tabular}

The hourly weather profile of Karnataka is used to test PV systems with WOA MPPT and WECS with fuzzy MPPT. Maximum power tracked by PV and wind systems are recorded in MATLAB for cost 
optimization analysis utilizing improved GA. For one day, cost optimization is examined. This research takes into account Karnataka's time-of-use tariff profile for private educational institutes. The following parameters are taken into account while optimizing the power and cost management controller:

Selling price $\left(F_{0}\right)=₹ 3.85$

$$
\text { Electricity tariff }\left(F_{\text {price }}\right)=\left\{\begin{array}{l}
₹ 6.2 \text {, between } 10 \mathrm{PM} \text { to } 6 \mathrm{AM} \\
₹ 7.2 \text {, between 6AM to 6PM } \\
₹ 8.2 \text {, between 6PM to 10PM }
\end{array}\right.
$$

Constraints of optimization are set as,

$$
\begin{aligned}
& P_{B A T M I N}=0.2 E, \\
& P_{B A T M A X}=0.8 E ;
\end{aligned}
$$

where Eis the rated capacity of the battery storage. In this analysis $\mathrm{E}$ is $2 \mathrm{~kW}$ and $\mathrm{P}_{\mathrm{BAT}}$ at the initial state of analysis $\left(P_{B A T, 0}\right)$ is $0.505 \mathrm{E}(1010 \mathrm{~W})$.

Parameters of improved GA are as shown in,

- Number of chromosomes: 20;

- Number of parents: 3;

- Crossover rate: 0.85

- Mutation rate: 0.2

Figure 4 depicts the hourly production of a renewable energy system for a single day. The total amount of renewable energy is equal to the sum of wind and solar energy. On this particular day, the greatest renewable energy produced was $3.7 \mathrm{kWh}$, while the least energy produced was $0.87 \mathrm{kWh}$. PV energy is generated from morning 7 a.m. until evening 6 p.m., as shown in Figure 4 (a). PV output at 7 a.m. and 6 p.m. is significantly lower than at other times of the day; at 12 p.m., the greatest PV power generated is 2717 watts. Figure 4 (b) depicts the wind energy's hourly power profile; it can be seen that power is more than $600 \mathrm{~W}$ throughout the day. Wind speed of $9.3 \mathrm{~m} / \mathrm{s}$ produces maximum wind power of $2160 \mathrm{~W}$ at 8 p.m. As demonstrated in Figure 4 (c), integrated renewable power is more than $800 \mathrm{~W}$ throughout the day due to the influence of wind energy. Figure 5 depicts the hourly load profile for a single day. The highest load on a day is $3 \mathrm{~kW}$, while the smallest load on a day is $0.73 \mathrm{kWh}$, as shown in Figure 5. The hourly TOU tariff profile is shown in Figure 6.

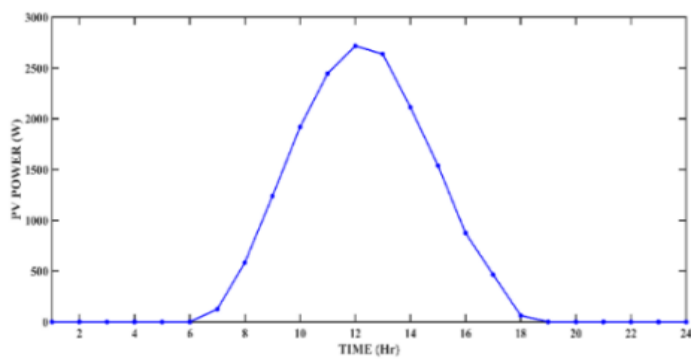

(a)

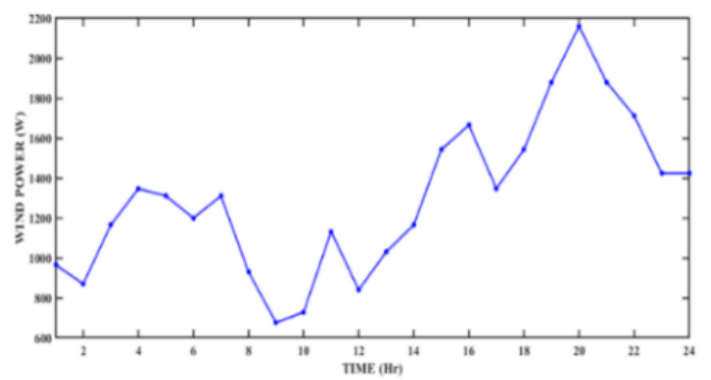

(b)

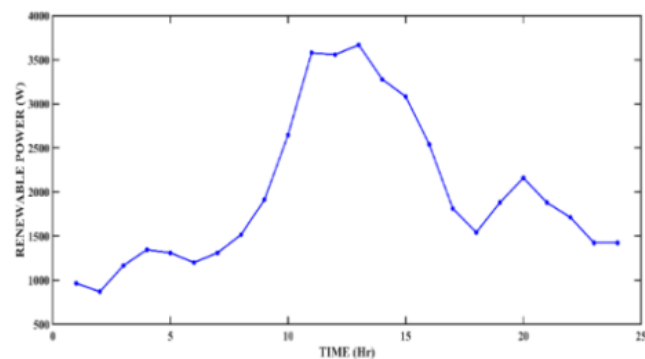

(c)

Figure 4. Hourly energy production; (a) PV power, (b) Wind Power, (c)Total renewable power 


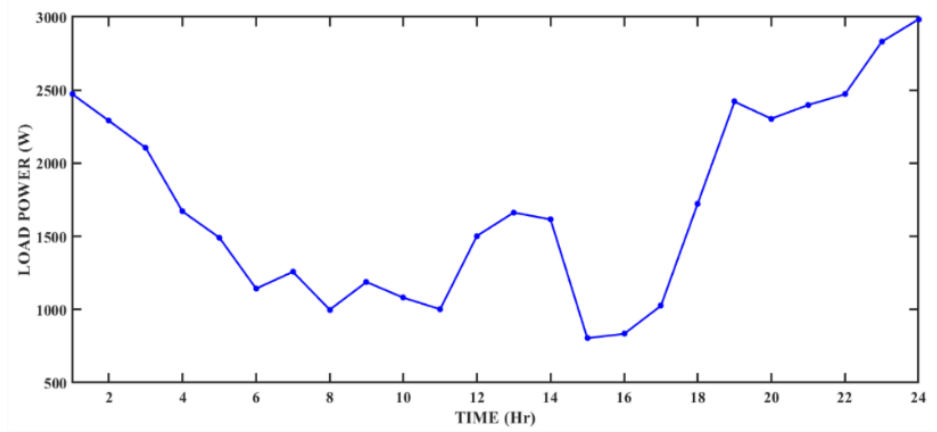

Figure 5. Hourly load profile

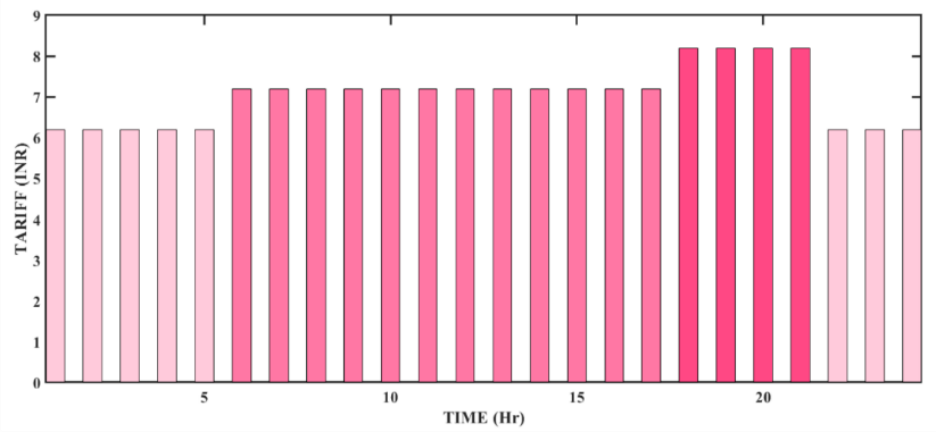

Figure 6. Hourly TOU tariff profile

Figure 6 shows that different tariffs 6.2, 7.2, and 8.2 are distributed throughout the day. Figure 6 indicates that the tariff is lowest from 10 p.m. to 6 a.m. in the morning, and highest from 6 p.m. to 10 p.m. in the evening. The tariff during rest hours is 7.2, which is modest in comparison to other tariffs. In this study, the hourly tariff profile is critical; when there is a need for power, an alternate source battery or grid is picked according to the tariff. If the tariff is low, electricity is obtained from the grid; otherwise, the load is supplied by the battery. So that battery discharge is optimized and purchasing costs are kept to a minimum.

Figure 7 (a) shows the performance of the improved GA with varied power in a single window. Figure 7 (b) depicts the improved GA optimized delivery ratio under the TOU tariff, whereas Figure 7 (c) depicts the battery charge profile. Figure 7 shows that there is a power demand from 6 p.m. to 5 a.m.; depending on the tariff, the battery is drained in the evening hours (6 p.m. to 10 p.m.) to decrease purchasing costs. As illustrated in Figure 7 (c), the battery drained its full power and reached a low value around $\mathrm{P}$ (BAT MIN). Power is purchased from the grid during the low tariff time, which runs from 10 p.m. to 5 a.m. In the case of power demand, as illustrated in Figure 7 (b), the delivery ratio $b_{t}$ is optimized to zero.

Figure 7 shows that there is surplus power from 6 a.m. to 5 p.m., which is used to charge the battery while the remaining electricity is sold to the grid. Because the analysis begins with a battery power of $1010 \mathrm{~W}$, if there is excess power, it priorities battery charging until $8 \mathrm{a} . \mathrm{m}$. while maintaining a low delivery ratio. Then, to boost selling power, the delivery ratio is raised. Since the battery reaches its maximum power P (BAT MAX) around 10 a.m., the delivery ratio is optimized to its maximum value of 1 . Because the battery is kept at its full capacity until 6 p.m., the entire extra power is sold to the grid with a delivery ratio of 1 . Based on the power available and battery power, the hourly profile of delivery ratio indicates that the delivery ratio ranges between 0 and 1 . When there is no extra power, the delivery ratio is optimized to zero. In the event of surplus power, the delivery ratio is increased from 0 and reaches 1 when the battery achieves maximum power, based on battery condition. Figure 8 depicts an hourly cost profile in INR. The cost ranges between +10 and -10 INR, as seen in Figure 8 . The cost in + denotes the sale price, whereas the cost in-denotes the purchase price. Figure 8 illustrates that from 6 p.m. to 10 p.m., there are no selling or purchasing costs since, as explained, the battery fulfills the power requirement. Due to the high tariff, no power is purchased during this time. Figure 8 shows that power is purchased from the grid during the low tariff period of 10 p.m. to 5 a.m., which is displayed as a negative value. Even if there is extra power between 6 and 8 a.m., because the selling price is low, priority is given to battery charging by low $\mathrm{b}$ values. From 9 a.m. to 5 p.m reasonable selling cost is yielded, shown as positive bars. The overall benefit per day by using improved GA is INR 2.01 . 
Apart from power and cost management controller optimization, the selling price of power determines the system's cost benefit. The selling price is determined by the amount of subsidy obtained and the type of renewable energy source used. As a result, the impact of the selling price is investigated using various costs such as ₹3.45, ₹3.9 and ₹4.15. The same system is analyzed using SFC\&RFS mode for all selling prices to validate the efficacy of the proposed improved GA.

At various selling prices, Figure 9 compares the performance of improved GA and SFC\&RFS mode. It can be shown that increasing the selling price improves the daily benefit using both approaches. For a selling price of ₹3.45, the SFC\&RFS approach yields a daily benefit of 0.78 , whereas the proposed GA method yields a daily benefit of ₹2.01. SFC\&RFS technique gives a daily benefit of ₹7.25 and ₹10.85 for a selling price of ₹3.9 and ₹4.15. Improved GA delivers economic benefits such as ₹8.87 and ₹12.6 for the aforementioned benchmark prices. From Figure 9, it is observed that under all benchmarking prices improved GA offers increased daily benefit, which validates the efficacy of proposed optimization. The benchmarking price of 3.9, highlighted (encircled) in Figure 9 is considered for comparative analysis. Economic benefits of improved GA in comparison with SFC\&RFS method are shown in Table 2. In Table 2 indicates that the existing SFC\&RFS technique provides a daily economic benefit of ₹7.25, whereas the optimization employing improved GA provides an economic benefit of ₹8.87. The proposed power and cost control system boosts the benefit to ₹ 1.62 .

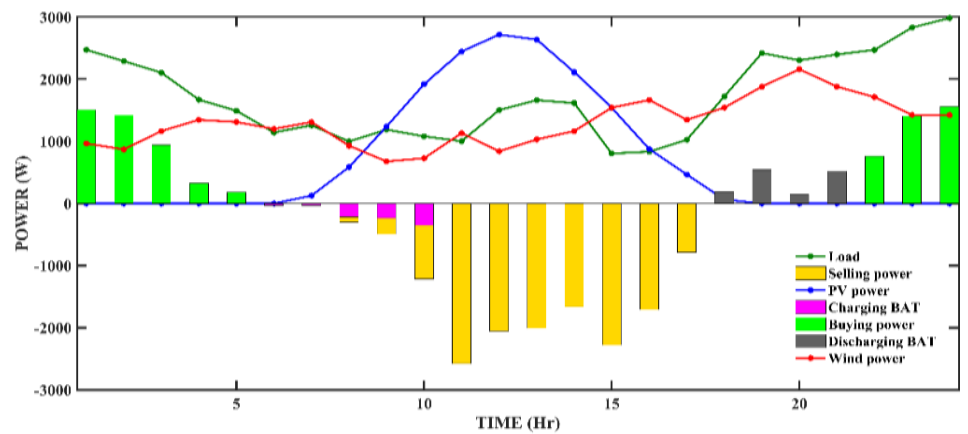

(a)

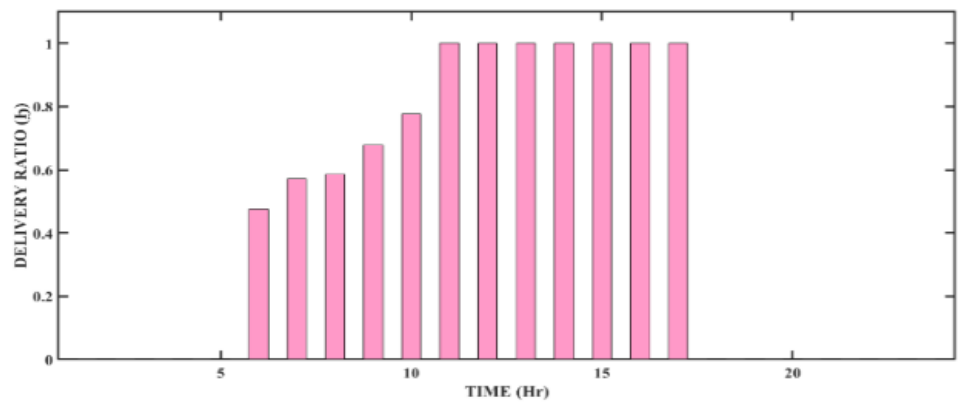

(b)

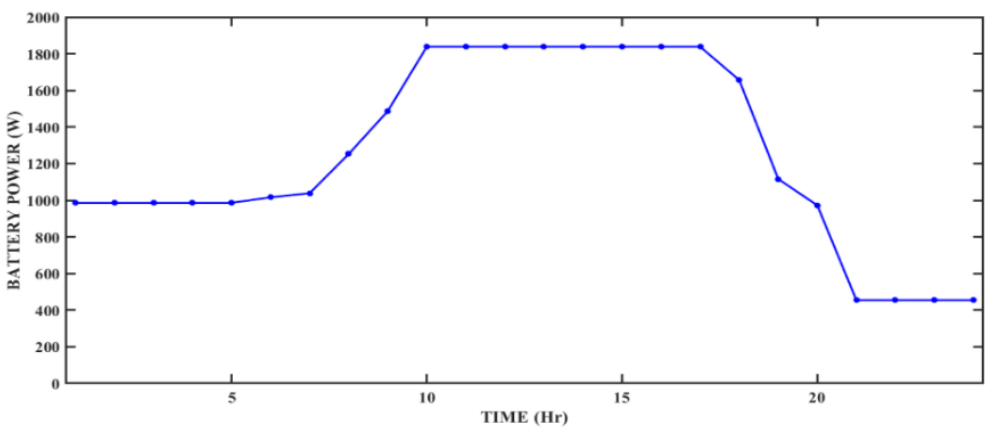

(c)

Figure 7. Performance of improved GA under TOU tariff (a) hourly power profile using improve GA (b) delivery ratio (c) hourly charge profile of the battery 


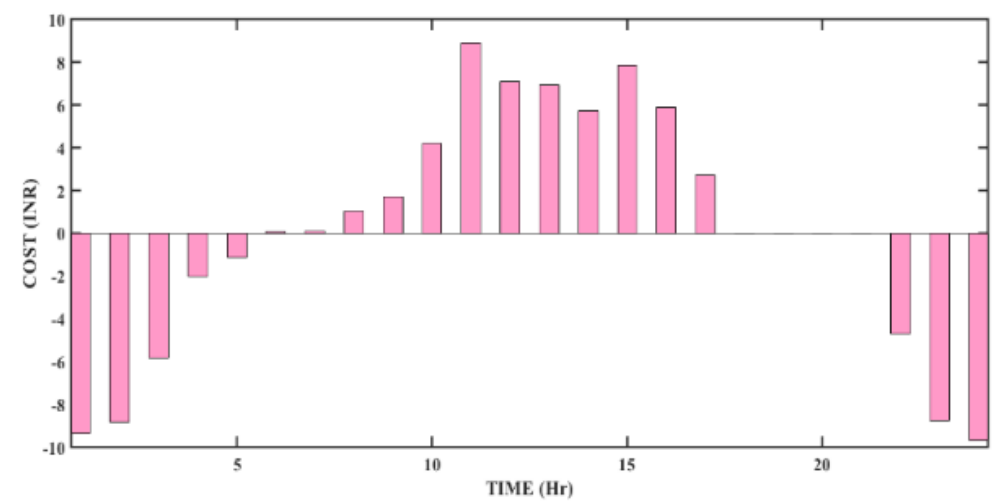

Figure 8 . Hourly profile of cost (INR)

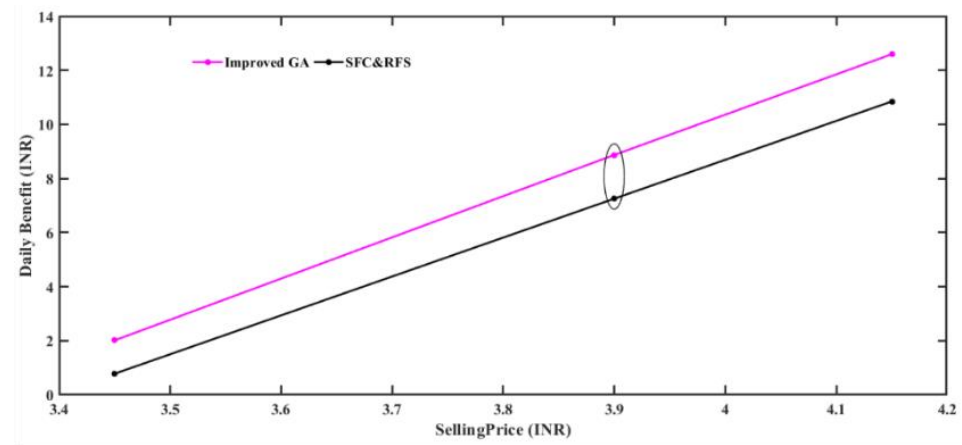

Figure 9. Comparative performance of improved GA and SFC\&RFS mode under various selling price

Table 2 shows that the proposed technique provides a revenue growth rate of $22.34 \%$. The revenue growth rate of grid connected renewable energy systems studied in Zhang and Tang [26] is considered in this research to validate the efficacy of suggested improved GA in comparison to conventional GA. In [26] revenue growth rate of GA based power and cost management system is presented in comparison with SFC\&RFS method, which is $17.47 \%$. The revenue growth rate of improved GA and GA in comparison with SFC\&RFS method is shown in Table 3.

Table 2. Economic benefits of improved GA in comparison with SFC\&RFS method

\begin{tabular}{ccc}
\hline Operation mode & $\begin{array}{c}\text { Daily benefits/ } \\
\text { INR }\end{array}$ & $\begin{array}{c}\text { Revenue growth } \\
\text { rate/\% }\end{array}$ \\
\hline SFC\&RFS & 7.25 & - \\
improved GA & 8.87 & 22.34 \\
\hline
\end{tabular}

Table 3. The revenue growth rate of improved GA and GA in comparison with SFC\&RFS method

\begin{tabular}{cc}
\hline Operation mode & Revenue growth rate/\% \\
\hline SFC\&RFS & - \\
GA [26] & 17.47 \\
improved GA & 22.34 \\
\hline
\end{tabular}

Table 3 indicates that, when compared to the SFC\&RFS approach, GA optimized power and cost management controllers give a revenue growth rate of $17.47 \%$, showing the success of power and cost management controller optimization over SFC\&RFS. In comparison to the SFC\&RFS approach, the proposed improved GA optimized power and cost management controller produces a revenue growth rate of $22.34 \%$ for the same selling price. According to the results of the investigation, the suggested improved GA technique provides a greater economic advantage not only when compared to the SFC\&RFS approach but also when compared to GA-based optimization. Improved GA improves optimization accuracy, resulting in a $4.87 \%$ in revenue growth rate as compared to GA optimized power and cost management in a hybrid renewable power system.

\section{CONCLUSION}

The main goals of a small-scale hybrid power system are efficient energy usage and cost reduction. This research considers a grid-associated PV-wind energy system with a battery. Whale optimization 
algorithm and fuzzy logic controller are used as MPPT in PV and wind energy systems, respectively, to track maximum power. Intelligent power management controllers are necessary to maximize the use of solar and wind energy. Intelligent power management controllers are required not only for efficient use of resources but also for financial gain. In this study, an improved genetic algorithm for power and cost management is proposed. The objective function and optimization variable are, respectively, the total energy cost and the delivery ratio. In a conventional genetic algorithm, the local optima problem may lower the power system's cost benefit. As a result, for improved cost benefit, an improved genetic algorithm with multi-parent crossover is presented in this paper. The research is based on one-day irradiance and wind speed data from Karnataka. WOA and FLC MPPT based PV and wind energy analyzed using real-time weather are applied as input to improved GA based power and cost management system. The economic benefit of the proposed improved GA system is presented with the comparative analysis of conventional SFC\&RFS mode and genetic algorithm-based energy management controller. In a PV-wind energy system, the daily benefit from the standard SFC\&RFS approach is ₹7.25, however, it is improved to ₹8.87 with the proposed improved GA based energy management controller. With the help of optimization in the energy management system, the economic benefit of a day is improved by ₹1.62 compared to the existing SFC\&RFS technique. The proposed system's daily revenue growth rate is $22.34 \%$, compared to $17.47 \%$ for a conventional GA-based energy management system with a TOU pricing. When compared to the GA optimized power and cost management system, the proposed improved GA enhances economic benefit by $4.87 \%$. Using multiparent crossover in optimization to avoid local optima enhances the cost benefit of the planned power system. As a result, it's proven that the proposed improved GA technique outperforms both the SFC\&RFS method and GA-based optimization in terms of economic gain. Meanwhile, the study shows that the battery never hits the minimal battery power level, which extends the battery's life and enhances its performance. As an outcome, the proposed improved GA-based power and cost management system effectively uses all power sources while providing increased economic benefits.

\section{REFERENCES}

[1] I. Sofimieari, M. W. Bin Mustafa, and F. Obite, "Modelling and analysis of a PV/wind/diesel hybrid standalone microgrid for rural electrification in Nigeria," Bulletin of Electrical Engineering and Informatics, vol. 8, no. 4, pp. 1468-1477, 2019, doi: 10.11591/eei.v8i4.1608.

[2] X. Song, Y. Zhao, J. Zhou and Z. Weng, "Reliability Varying Characteristics of PV-ESS-Based Standalone Microgrid," IEEE Access, vol. 7, pp. 120872-120883, 2019, doi: 10.1109/ACCESS.2019.2937623.

[3] A. A. Jamali, N. M. Nor and T. Ibrahim, "Energy storage systems and their sizing techniques in power system-A review," 2015 IEEE Conference on Energy Conversion (CENCON), 2015, pp. 215-220, doi: 10.1109/CENCON.2015.7409542.

[4] C. Ameur, S. Faquir, and A. Yahyaouy, "Intelligent optimisation and management system for renewable energy systems using multi-agent," IAES International Journal of Artificial Intelligence, vol. 8, no. 4, pp. 352-359, 2019, doi: 10.11591/ijai.v8.i4.pp352-359.

[5] M. S. A. Mustaza, M. A. M. Arif, S. N. Ramli, "An extensive review of energy storage system for the residential renewable energy system," Indonesian Journal of Electrical Engineering and Computer Science, vol. 18, no. 1, pp. 242-250, 2020, doi: 10.11591/ijeecs.v18.i1.pp242-250.

[6] M. Karabacak, L. M. Fernández-Ramírez, T. Kamal and S. Kamal, "A New Hill Climbing Maximum Power Tracking Control for Wind Turbines with Inertial Effect Compensation," IEEE Transactions on Industrial Electronics, vol. 66, no. 11, pp. 8545-8556, Nov. 2019, doi: 10.1109/TIE.2019.2907510.

[7] J. Chen, T. Lin, C. Wen and Y. Song, "Design of a Unified Power Controller for Variable-Speed Fixed-Pitch Wind Energy Conversion System," IEEE Transactions on Industrial Electronics, vol. 63, no. 8, pp. 4899-4908, Aug. 2016, doi: 10.1109/TIE.2016.2547365.

[8] Y. Saidi, A. Mezouar, Y. Miloud, K. D. E. Kerrouche, B. Brahmi, and M. A. Benmahdjoub, "Advanced nonlinear backstepping control design for variable speed wind turbine power maximisation based on tip-speed-ratio approach during partial load operation," International Journal of Dynamics and Control, vol. 8, no. 2, pp. 615-628, 2020, doi: 10.1007/s40435-019-00564-3.

[9] M. Azzouz, A. Elshafei and H. Emara, "Maximum-power tracking of wind energy conversion systems based on fuzzy algorithms," 2010 IEEE International Symposium on Intelligent Control, 2010, pp. 481-486, doi: 10.1109/ISIC.2010.5612919.

[10] S. Dorahaki, "A survey on maximum power point tracking methods in photovoltaic power systems," Bulletin of Electrical Engineering and Informatics, vol. 4, no. 3, pp. 169-175, 2015, doi: 10.11591/eei.v4i3.499.

[11] Gilfred Allen Madrigal, K. G. Cuevas, V. Hora, K. M. Jimenez, J. N. Manato, M. J. Porlaje, and B. N. Fortaleza, "Fuzzy logic-based maximum power point tracking solar battery charge controller with backup stand-by AC generator," Indonesian Journal of Electrical Engineering and Computer Science, vol. 16, no. 1, pp. 136-146, 2019, doi: 10.11591/ijeecs.v16.i1.pp136-146.

[12] K. H. Chalok, M. Faridun, M. F. N. Tajuddin, S. B. Thanikanti, Md. Shahrin, and T. Sutikno, "Optimal extraction of photovoltaic energy using fuzzy logic control for maximum power point tracking technique," International 
Journal of Power Electronics and Drive Systems, vol. 11, no. 3, pp. 1628-1639, 2020, doi: 10.11591/ijpeds.v11.i3.1628-1639.

[13] S. Motahhir, et al., "Optimal Energy Harvesting from a Multistrings PV Generator Based on Artificial Bee Colony Algorithm," IEEE Systems Journal, doi: 10.1109/JSYST.2020.2997744.

[14] S. Obukhov, A. Ibrahim, A. A. Zaki Diab, A. S. Al-Sumaiti and R. Aboelsaud, "Optimal Performance of Dynamic Particle Swarm Optimization Based Maximum Power Trackers for Stand-Alone PV System Under Partial Shading Conditions," IEEE Access, vol. 8, pp. 20770-20785, 2020, doi: 10.1109/ACCESS.2020.2966430.

[15] S. Mirjalili and A. Lewis, "The whale optimisation algorithm," Advances in engineering software, vol. 95, pp. 5167, 2016, doi: 10.1016/j.advengsoft.2016.01.008.

[16] R. Dufo-López and J. L. Bernal-Agustín, "Multi-objective design of PV-wind-diesel-hydrogen-battery systems," Renewable energy, vol. 33, no. 12, pp. 2559-2572, 2008, doi: 10.1016/j.renene.2008.02.027.

[17] R. Dufo-Lopez, J. L. Bernal-Agustín, and J. Contreras, "Optimisation of control strategies for standalone renewable energy systems with hydrogen storage," Renewable energy, vol. 32, no. 7, pp. 1102-1126, 2007, doi: 10.1016/j.renene.2006.04.013.

[18] J. L. Bernal-Agustín and R. Dufo-López, "Hourly energy management for grid-connected wind-hydrogen systems," International Journal of Hydrogen Energy, vol. 33, no. 22, pp. 6401-6413, 2008, doi: 10.1016/j.ijhydene.2008.08.026.

[19] S. R. Salkuti, "Optimal operation management of grid-connected microgrids under uncertainty," Indonesian Journal of Electrical Engineering and Computer Science, vol. 16, no. 3, pp. 1163-1170, 2019, doi: 10.11591/ijeecs.v16.i3.pp1163-1170.

[20] M. R. BasirKhan, J. Pasupuleti, J. Al-Fattah, and M. Tahmasebi, "Energy management system for PV-Battery microgrid based on model predictive control," Indonesian Journal of Electrical Engineering and Computer Science, vol. 15, no, 1, pp. 20-25, 2019, doi: 10.11591/ijeecs.v15.i1.pp20-26.

[21] J. E. Haysom, K. Hinzer, and D. Wright, "Impact of electricity tariffs on optimal orientation of photovoltaic modules," Progress in Photovoltaics: Research and applications, vol. 24, no. 2, pp. 253-260, 2016, doi: 10.1002/PIP.2651

[22] L. Butler and K. Neuhoff, "Comparison of feed-in tariff, quota and auction mechanisms to support wind power development," Renewable energy, vol. 33, no. 8, pp. 1854-1867, 2008, doi: 10.1016/j.renene.2007.10.008.

[23] J. D. Mondol, Y. G. Yohanis, and B. Norton, "Optimising the economic viability of grid-connected photovoltaic systems," Applied Energy, vol. 86, pp. 985-999, 2009, doi: 10.1016/j.apenergy.2008.10.001.

[24] N. R. Dartmouth, R. Wiser, amd G. Barbose, "Customer economics of private photovoltaic systems: Sensitivities to changes in wholesale market design and rate structures," Renewable and Sustainable Energy Reviews, vol. 54, pp.1459-1469, 2016, doi: 10.1016/j.rser.2015.10.111.

[25] A. Chakir, et al., "Optimal energy management for a grid connected PV-battery system," Energy Reports, vol. 6, pp. 218-231, 2020, doi: 10.1016/j.egyr.2019.10.040.

[26] S. Zhang and Y. Tang, "Optimal schedule of grid-connected private PV generation systems with battery storages under time-of-use and step tariffs," Journal of Energy Storage, vol. 23, pp. 175-182, 2019, doi: 10.1016/j.est.2019.01.030.

[27] E. K. Burke, S. Gustafson and G. Kendall, "Diversity in genetic programming: an analysis of measures and correlation with fitness," in IEEE Transactions on Evolutionary Computation, vol. 8, no. 1, pp. 47-62, Feb. 2004, doi: 10.1109/TEVC.2003.819263.

[28] P. S. Kumar, R. P. S. Chandrasena, V. Ramu, G. N. Srinivas and K. V. S. M. Babu, "Energy Management System for Small Scale Hybrid Wind Solar Battery Based Microgrid," IEEE Access, vol. 8, pp. 8336-8345, 2020, doi: 10.1109/ACCESS.2020.2964052.

[29] N. A. Prashanth and P. Sujatha, "Commonly used wind generator systems: A comparison note," Indonesian Journal of Electrical Engineering and Computer Science, vol. 7, no. 2, pp. 299-311, 2017, doi: 10.11591/ijeecs.v7.i2.pp299-311.

[30] H. Soleimanzad, J. Bosche, M. Dahmane, and A. El Hajjaji, "Dynamic output feedback control for a micro wind turbine," Energy Procedia, vol. 83, pp.350-359, 2015, doi: 10.1016/j.egypro.2015.12.189.

[31] M. Engin, "Sizing and simulation of PV-wind hybrid power system," International Journal of Photoenergy, vol. 2013, pp. 1-10, 2013, doi: 10.1155/2013/217526.

[32] S. Gorai, S. Dasarathan, S. Venkatarajan, V. Sugavanam, G. R. P. Kumar, M. Sudhakaran, "Investigation of voltage regulation in grid connected PV system," Indonesian Journal of Electrical Engineering and Computer Science, vol. 19, no. 3, pp. 1131-1139, 2020, doi: 10.11591/ijeecs.v19.i3.pp1131-1139.

[33] P. C. Chang, S.-H. Chen, C.-Y. Fan, and C. L. Chan, "Genetic algorithm integrated with artificial chromosomes for multi-objective flow shop scheduling problems," Applied Mathematics and Computation, vol. 205, no. 2, pp. 550561, 2008, doi: 10.1016/j.amc.2008.05.027. 


\section{BIOGRAPHIES OF AUTHORS}

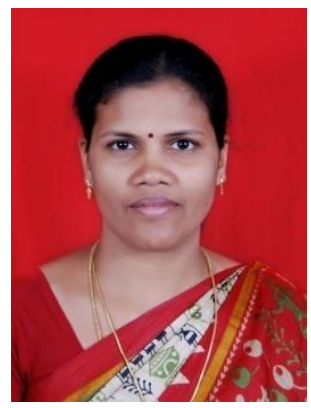

Kothai Andal C. received her B.E degree in Electrical and Electronics Engineering from Dr. Sivanti Aditanar College of Engineering, Tamilnadu in 2001 and M.E degree from Government College of Engineering, Tamilnadu, with specialization in Power Electronics and Drives and pursuing Ph. D at RV College of Engineering, Bengaluru, VTU, Karnataka, India. She is presently working as Assistant Professor at AMC Engineering College. Bengaluru, Karnataka. She has 16 years of teaching experience and in Member of IEEE, MIE \& ISTE. Her areas of interest are Microgrid, Power Electronics and Control System.

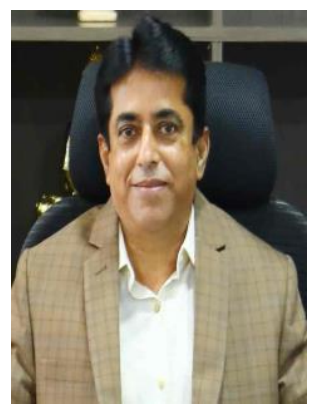

Jayapal R. completed B.E in Electrical Engineering and M.E in Power Systems in the year 1984 and 1986 respectively from University Visvesvaraya College of Engineering, Bangalore University. He Joined RV College of Engineering, Bangalore as Lecturer in Electrical Engineering Department in 1986 and was selected as Assistant professor in 1992 and re designated as Associate Professor in 2010. He completed PhD titled "Design and Implementation of Robust Power System stabilizer using H infinity Loop Shaping Technology" from VTU in 2012. He served as Professor and Head of Electrical and Electronics Engineering Department from 2012 to 2018. He is working as Principal of RV Institute of Technology and Management (RVITM) from Sept 2018.He has guided 37 UG and 16 PG projects. He is an avid researcher and academician with 34+ years of experience in thriving high profile research that has social cause and brings a succeeding impactful outcome to the Digital Technology Industry. He has published many publications in reputed journals ad conferences which are being cited by global researchers. He carries the pride of publishing a Patent titled 'Fuel Efficient Heavy-Duty Vehicles Adaptable to Both Agricultural and On Road Applications' in 2019 (https://ipindiaservices.gov.in/publicsearch) Application \#: 201941009857 and has mentored on "Design and development of igniter exciter spark production system" to M/s. Durag India Instrumentation Pvt. Ltd, Bengaluru which is developed into a product. 